\title{
Identidade jovem em canções de rock dos anos 1980
}

\author{
Youngster identities in 1980's rock songs
}

ANTOONIO FERNANDES JÚNIOR*

Resumo: $O$ presente trabalho busca, a partir de fragmentos de algumas canções de rock dos anos 1980 no Brasil, observar a emergência de uma subjetividade jovem, materializada no discurso das canções, observando as "posições-sujeito" adotadas e os efeitos identitários construídos.

Abstract: Within the study of fragments of 1980's brazilian rock songs, the present paper tries to observe the emergence of a youngsters subjectivity embodied in the songs discourse, as well as the setup identity effects.

Palavras-chave: Subjetividade, Identidade, Canções.

Keywords: Subjects, Identity, Songs.

* Professor do Departamento de Letras da Universidade Federal de Goiás, Campus Catalão. 
O trabalho com e sobre a Música Popular Brasileira caracteriza-se como algo extremamente instigante e desafiador. Instigante pela riqueza expressiva e artística que a envolve, e desafiador pela diversidade de estilos, ritmos e influências presentes nas suas produções. Desde o advento da Bossa Nova (década de 1960), a música popular conseguiu ampliar seu campo sonoro, incorporando ritmos estrangeiros como o jazz, o rock, a música pop internacional, os ritmos africanos, entre outros, responsáveis pela diversidade musical existente no Brasil. A grande riqueza da música brasileira está justamente no seu caráter múltiplo que, aliás, é um reflexo da realidade sócio-cultural do país. Da modinha ao rock, a canção no Brasil percorre uma galeria de estilos e formas, cujo cruzamento torna-a de difícil classificação. Dificuldade que, longe de ser um aspecto negativo, só vem reforçar suas qualidades.

Para discutir o rock dos anos 1980, torna-se necessário, ainda que de passagem, refletir um pouco sobre a década de 1970, o período da censura e, posteriormente, a abertura política, antecedentes diretamente ligados ao objeto de nosso estudo. No discurso poético das letras das canções de rock dos anos 1980, encontram-se marcas linguístico-discursivas que apontam para o estabelecimento de uma identidade jovem, marcada, nitidamente, pelo confronto com a geração militar. Nesse sentido, o presente trabalho busca, a partir de fragmentos de algumas canções, observar esse movimento de subjetividade jovem, materializada no discurso das canções, observando as "posições-sujeito" adotadas e os efeitos identitários construídos.

\section{O contexto de surgimento do rock dos anos 1980: apontamentos}

A década de 1970 caracterizou-se como um período nebuloso e conturbado. A relação existente entre censura/cultura revelou-se pouco amistosa, dificultando a produção artística, principalmente de conotação política, nos mais variados setores culturais. $O$ crescimento da mídia, nesse período, ocorreu em larga escala. A expansão da televisão, do cinema, do setor editorial, fonográfico, etc., juntamente à criação de órgãos ligados ao setor cultural (Conselho Federal de Cultura, EMBRAFILME, FUNARTE, Pró-Memória) remetem ao desenvolvimento do capitalismo "tardio" no Brasil, como também às transformações ocorridas na sociedade brasileira durante o regime militar. Ortiz (1994) salienta que o setor 
cultural enfrentou um caminho duplo, pois, de um lado, o Estado Militar atuava com a censura, a repressão, exílios, prisões; e, do outro lado, a expansão econômica e o crescimento industrial fortaleciam os setores de produção de cultura e "o mercado de bens culturais".

O que caracteriza a situação cultural nos anos 60 e 70 é o volume e a dimensão do mercado de bens culturais. Se até a década de 50 as produções eram restritas, e atingiam um número reduzido de pessoas, hoje elas tendem a ser cada vez mais diferenciadas e cobrem uma massa consumidora. Durante o período que estamos considerando, ocorre uma formidável expansão, a nível de produção, de distribuição e de consumo da cultura; é nesta fase que se consolidam os grandes conglomerados que controlam os meios de comunicação e da cultura popular de massa (Ortiz, 1994, p. 121).

Tais fatores, de uma forma ou de outra, acompanharão a produção, a distribuição e o consumo de "bens culturais" até os nossos dias. No tocante à questão musical, a televisão exerce uma forte influência no gosto popular, pois, ao atuar em rede nacional com as trilhas sonoras das telenovelas e demais programas, interfere, em larga escala, na formação dos sucessos musicais, impondo a maior parte das canções que integrará as paradas de sucesso. Para Ortiz (1994), um dos veículos de comunicação que melhor caracteriza e consolida a indústria cultural no Brasil é o desenvolvimento da televisão que passa a atuar em vários setores da sociedade, tornando-se um "aparelho ideológico" com potência máxima.

Por atuar em rede nacional, condição básica para a existência da indústria cultural, a televisão desperta interesses dos setores políticos e empresarial. No primeiro caso, busca consolidar a ideologia do governo Militar e, no segundo, a integração de um mercado consumidor. De um lado tem-se um interesse "moral" e no outro, mercadológico. Não é de se entranhar que o crescimento da mídia, via concessões de rádio e televisão, aconteça justamente no período Militar. As emissoras pretendem, segundo Ortiz, conquistar o mercado a qualquer preço, aceitando cumprir compromissos adquiridos anteriormente junto ao Estado Militar (Ortiz, 1994, p. 120). Para tanto, irão controlar a programação e garantir o pacto com os militares, evitando programas "degradantes para a formação do 
homem brasileiro definido segundo a Ideologia da Segurança Nacional"1.

Em 1979 temos o fim da censura, e, com ela, a anistia política, o que abre espaço, no início da década de 1980, para a explosão do rock brasileiro. Para Aguiar, "os anos 1980 começam com a distensão política e com ela o culto do prazer: é hora de 'descobrir' o corpo sufocado pelo período anterior; é hora do divertimento e do bom humor. Clima ideal para a instauração mais profissionalizada do rock no Brasil" (Aguiar, 1994, p. 152).

Na década de 1980, são muitos os grupos de rock que se projetam no cenário musical, trazendo consigo influências do movimento punk inglês de 1976, sobretudo da banda Sex Pistols. Assim, veem-se neste contexto bandas como Gang 90 \& Absurdetes (consagrados com a canção Perdidos na Selva), Lulu Santos, 14 Bis, Blitz, Kid Abelha \& os Abóboras Selvagens, RPM, Ritchie, Léo Jaime, Paralamas do Sucesso, Titãs, Legião Urbana, Ultrage a Rigor, Barão Vermelho, Lobão, Engenheiros do Hawaii, entre outros. É verdade que muitos grupos tiveram vida curta e não conseguiram consolidar-se no plano artístico, por problemas de mercado, relação com gravadoras, questões internas aos próprios grupos, enfim questões que fogem aos propósitos deste estudo.

Em um primeiro momento, não faltaram associações com o movimento da Jovem Guarda, e a nova geração do rock foi aclamada como "a nova Jovem Guarda". Além da ligação do rock com o movimento liderado por Roberto Carlos, nos anos 1960, vieram as previsões de sua vida curta, como se fosse apenas uma onda passageira. Enfim, bem recebida ou não a nova geração do rock brasileiro veio para ficar, conquistou aos poucos o seu espaço na mídia e na sociedade, adquiriu credibilidade e seguiu em frente.

O grande impacto do início da década de 1980 veio com a banda Blitz. Com apenas um compacto lançado, a canção Você não soube me amar desperta o interesse das gravadoras que saem em busca de novos grupos do mesmo gênero. Vários grupos são contratados, criando, assim, um mercado específico de rock

\footnotetext{
1 "Resumidamente se pode dizer que essa ideologia concebe o Estado como uma entidade política que detém o monopólio da coerção, isto é, a faculdade de impor, inclusive pelo emprego da força, as normas de conduta a serem obedecidas por todos [...] De uma certa forma, o que a Ideologia da Segurança Nacional se propõe é substituir o papel que as religiões desempenham nas sociedades 'tradicionais' [...] Procura-se garantir a integridade da nação na base de um discurso repressivo que elimina as disfunções, isto é, as práticas dissidentes, organizando-as em torno de objetivos pressupostos como comuns e desejados por todos" (Ortiz, 1994, p, 115).
} 
no Brasil. Outro grupo de grande impacto no período entre 1984 e 1986 foi o RPM. O grupo de Paulo Ricardo, com apenas dois discos lançados, atingiu a cifra de 3 milhões de discos vendidos no ano de 1986, sendo que o segundo disco, espantosamente, foi uma versão gravada ao vivo do primeiro. Façanha inédita para os padrões mercadológicos da época.

No período de 1985/1986 acontece o grande "boom" do rock nacional com o surgimento da grande maioria das bandas de rock do país, incluindo grupos que ainda atuam no meio artístico atual. Nesse sentido, cria-se no país um mercado discográfico jovem ${ }^{2}$, programas de videoclipe, revistas especializadas, rádios, etc., enfim todo um aparato direcionado ao rock e a seu público jovem. É interessante lembrar que, no ano de 1985, realizou-se no Rio de Janeiro o primeiro Rock in Rio, um megaevento de rock incluindo shows de grandes grupos nacionais e estrangeiros. O evento realizou-se em um período característico, uma vez que já havia um público de rock considerável no país, ou melhor, uma cultura rock. Segundo Souza (1995), o rock torna-se intimamente ligado ao jovem, podendo-se afirmar a existência de uma cultura rock no país, ou seja, algo que ultrapassa as fronteiras da audição e ganha espaço nas ruas, nas formas de comportamento, nas roupas, etc. É uma cultura que vai além dos elementos externos, configurando-se como um sistema que inicia o adolescente na sociedade (movimento de subjetivação), modula suas atitudes e também o orienta para a compreensão política do mundo. É importante ressaltar a existência de outros movimentos, antes da década de 1980, voltados para os jovens e que geraram uma cultura: os hippies, a rebeldia romântica da Jovem Guarda, o teor político da Tropicália etc. Portanto, ao nos referirmos ao termo cultura jovem não desconsideramos tais movimentos, pois foi a partir deles que o rock dos anos 1980 conseguiu desenvolver-se. A cultura rock não é exclusiva dos anos 1980, mas, nesse período, teve um desenvolvimento considerável.

Esse desenvolvimento está intimamente ligado ao crescimento da mídia no país e à implantação da indústria cultural, conforme assinalado anteriormente. Como as demais produções artísticas, o rock encontra no crescimento da mídia

\footnotetext{
${ }^{2}$ Nas décadas anteriores, houve, também, um mercado discográfico jovem, pois Caetano Veloso, Gilberto Gil e Roberto Carlos, ainda jovens, cantaram para o público jovem. Na verdade, o rock, o movimento hippie, oriundos dos anos 60, tiveram uma ligação e uma importância muito grande na e para a história da juventude.
} 
reflexo do capitalismo "selvagem", espaço de manifestação e torna-se um mercado promissor na década de 1980. Além de discos, surgem a indústria de videoclipes, revistas especializadas, roupas, etc.; enfim, um conjunto de produtos ligados ao rock com o foco direcionado para um grande mercado consumidor, o público jovem.

O crescimento e desenvolvimento acelerado da tecnologia, a expansão da indústria cultural, o processo de globalização e demais correlatos alteram e passam a redimensionar visões de mundo, convicções e a relação do sujeito com a realidade.

A fábrica global instala-se além de toda e qualquer fronteira, articulando capital, tecnologia, força de trabalho social e outras forças produtivas. Acompanhadas pela publicidade, a mídia impressa e eletrônica e a indústria cultural, misturadas em jornais, revistas, livros, programas de rádio, emissões de televisão, videoclipes, fax, redes de computadores e outros meios de comunicação, informação e fabulação, dissolvem fronteiras, agilizam os mercados, generalizam o consumismo. Provocam a desterritorialização e a re-territorialização das coisas, gentes e idéias. Promovem o redimensionamento de espaços e tempos (lanni, 1997, p. 53).

Em função desse desenvolvimento, surge, principalmente nos grandes centros urbanos, um "novo sujeito", reflexo dessa nova "ordem mundial", que tem a mídia como um ponto de contato entre esse sujeito e a realidade, formando o triângulo sujeito-mídia-realidade, cuja existência funda-se nas vinculações ideológicas do mercado com os meios de comunicação de massa.

Quando se pensa em cultura de massa e, consequentemente, em indústria cultural, logo aparecem as seguintes questões: produção e distribuição em larga escala, produtos oferecidos a todo tipo de público (classe social), estandardização, descartabilidade e a concepção homogênea do público consumidor. "Satisfação garantida ou o seu dinheiro de volta" é o lema do "produto" negociado pelo mercado cultural. Do ponto de vista da produção, a indústria cultural opera com valores de homogeneidade procurando uniformizar a recepção e o mercado consumidor. Já do ponto de vista da recepção, o público consumidor de massa caracteriza-se, justamente, pela heterogeneidade, elemento que afasta quaisquer hipóteses de padronização.

No Brasil, onde as desigualdades sociais e o analfabetismo são altíssimos, o 
poder da indústria cultural é avassalador e atinge, principalmente por meio da TV, um número cada vez maior de pessoas. Assim, o poder de manipulação da indústria cultural é muito grande, pois ela assume as funções de polo educacional, diretamente ligada aos centros de poder (Pellegrini, 1999, p. 200). Manipulação que nos acompanha desde o período militar.

Sem dúvida alguma, a indústria cultural redimensiona a relação com o setor cultural, que passa a ser focalizado como mais uma forma de investimento e obtenção de lucro. Assim, as produções artísticas, independente da especificidade, passam pela lógica empresarial e, por último, são comercializadas. É preciso ter o cuidado de não colocar tudo no "mesmo saco", pois, "como nem tudo que reluz é ouro", nem tudo que passa pelas malhas da indústria cultural é apenas mercadoria pronta para o consumo e, consequentemente, descartável.

Nesse sentido, se pensarmos no rock enquanto arte de massa teremos, segundo Souza, uma modalidade artístico-musical produzida dentro dos padrões da indústria cultural, da sujeira do mercado, que instaura "uma unidade entre fruição e crítica, divertimento e destruição de algumas assombrações cotidianas construídas pelo capitalismo contemporâneo" (Souza, 1995, p. 30).

\section{Subjetividade nas canções de rock: esboço de leitura}

As discussões foucaultinas sobre "enunciado" e "discurso" oferecem pistas instigantes para pensar a noção de autoria e, para o que nos interessa no momento, a questão do sujeito. $O$ enunciado, diferentemente de uma frase ou um ato de fala, caracteriza-se por ser produzido por um sujeito (função enunciativa), que fala de um dado lugar e é determinado "por regras sócio-históricas que definem e possibilitam que ele seja enunciado" (Gregolin, 2004, p. 89).

Nesse sentido, o discurso não é visto como algo estanque, mas como uma prática discursiva. Nela é definido o lugar de onde o sujeito enuncia, ou seja, a posição que ocupa na instância de enunciação. O sujeito é visto como uma função, e um mesmo indivíduo pode ocupar diferentes posições, pois o discurso é um "campo de regularidade para diversas posições de subjetividade" (Gregolin, 2004, p. 61). A problemática do sujeito foi um dos temas centrais das pesquisas de Foucault em sua trajetória intelectual. Para Foucault (2004), o sujeito não é uma substância. 
É uma forma, e essa forma nem sempre é, sobretudo, idêntica a si mesma. Você não tem consigo próprio o mesmo tipo de relações quando você se constitui como sujeito político que vai votar ou toma a palavra em uma assembléia, ou quando você busca realizar o seu desejo em uma relação sexual. Há, indubitavelmente, relações e interferências entre essas diferentes formas de sujeitos; porém, não estamos na presença do mesmo tipo de sujeito. Em cada caso, se exercem, se estabelecem consigo mesmo formas de relação diferentes. E o que me interessa é, precisamente, a constituição histórica dessas diferentes formas de sujeito, em relação aos jogos de verdade (Foucault, 2004, p. 275).

O enunciado é um espaço vazio, apto a ser preenchido por diferentes posições-sujeito. Se há uma dispersão de lugares e enunciados que circulam em um dado contexto histórico, o sujeito pode ocupar diferentes posições. O enunciado, para atestar sua existência, necessita de um autor, uma instância produtora. Segundo Foucault, existem diferentes posições do sujeito dispersos em um romance; mas o mesmo não ocorre em um tratado de matemática, conforme exemplifica em Arqueologia do Saber. Estas mudanças estão correlacionadas aos gêneros do discurso, que têm estatutos diferenciados.

Outro elemento característico do enunciado é sua materialidade; ou seja, "ele precisa ter uma substância, um suporte, um lugar, uma data (Foucault, 2004, p. 117)". Além disso, o enunciado "tem sempre margens povoadas de outros enunciados" (Foucault, 2004, p. 112), pois reatualiza outros enunciados, outros discursos. Dessa maneira, o mesmo enunciado pode voltar (repetibilidade) com a mesma materialidade, mas já não é o mesmo, porque muda a instância enunciativa. É nesse sentido que o enunciado adquire singularidade, tornando-se um acontecimento que, por sua vez, delimita-se pelo fato de ter aparecido um determinado enunciado e não outro em seu lugar. Segundo Gregolin (2004),

trata-se de descrever o exercício da função enunciativa, suas condições, suas regras de controle, o campo em que ela se realiza pois entre o enunciado e o que ele enuncia não há apenas relação gramatical, lógica ou semântica; há uma relação que envolve os sujeitos, que passam pela História, que envolve a própria materialidade do enunciado (Gregolin, 2004, p. 90).

Tomando o sujeito como uma posição, tal como coloca Foucault, marcado 
historicamente pelas condições de produção de uma dada prática discursiva, pode-se verificar que uma certa produção do chamado rock brasileiro dos anos 1980 insere-se em uma perspectiva ambivalente, cujos efeitos de subjetividade apontam para diferentes caminhos: uma crítica ao sistema capitalista (adesão e negação), um rompimento com a geração militar e, de forma geral, um modo de pensar a condição do jovem enquanto sujeito no contexto da chamada geração perdida.

Se tomarmos as condições de produção, surgimento, divulgação e recepção do rock dos anos 1980, encontramos diferentes posições-sujeito adotadas no discurso das canções. E é no contexto pós-ditadura e do crescimento da mídia nos anos 1980 que os artistas conseguiram o terreno livre para a divulgação de suas propostas e/ou ideais em um momento político brasileiro "menos" conturbado do país.

A década de 1980 é vista por alguns críticos (Vargas, 1999) como a década maldita, pós-utópica, caracterizada pela crise das ideologias, morte das utopias. Para Vargas, a década de 1980 no Brasil foi o "momento em que uma geração inteira de jovens de classe média urbana, nascidos e formados após o golpe de 1964 , tiveram de reaprender a pensar o mundo e reinventar para si as formas de dizê-lo" (Vargas, 1999, p. 176). Na verdade, nascidos depois do enfraquecimento tanto das ideologias de direita quanto das de esquerda e depois que "o sonho acabou". Tal questão pode ser percebida nos versos da canção Ideologia, de Cazuza e Frejat:

Meu partido é um coração partido

E as ilusões estão todas perdidas.

Os meus sonhos foram todos vendidos

Tão barato que nem acredito.

Eu nem acredito que aquele garoto

Que ia mudar o mundo

Frequenta agora as festas do "grand monde"

Meus heróis morreram de "overdose" (refrão)

Meus inimigos estão no poder.

Ideologia, eu quero uma pra viver. 
O meu prazer agora é risco de vida

Meu "sex and drugs" não tem nenhum "rock'n roll".

Eu vou pagar a conta do analista

Pra nunca mais saber quem eu sou.

Pois aquele garoto que ia mudar o mundo,

Agora assiste a tudo em cima do muro. (refrão) (Cazuza et Frejat, 1988).

Desde os primeiros versos da canção Ideologia, podemos perceber a materialização de algumas questões vinculadas à década de 1980, principalmente, o enfraquecimento das ideologias. Em uma situação diferente da agitação política fervorosa dos anos 1960/1970, a geração "coca-cola" dos anos 1980 enfrenta um momento em que a aposta no futuro, por meio de revoluções e/ou transformação social, cede espaço ao momento pós-utópico ${ }^{3}$ de cantar o presente, o agora. Destaque para a rima mundo/muro: "Pois aquele garoto que ia mudar o mundo, / Agora assiste a tudo em cima do muro" (Cazuza et Frejat, 1988).

Ao espírito revolucionário de décadas anteriores, o poeta contrapõe a apatia ("em cima do muro"), estabelecendo um contraste entre passado e presente. Nos anos 1960, os ideais de revolução em prol da igualdade social tomam conta de uma geração, que venera ídolos como Janis Joplin, Jim Morison, etc. e que acredita na possibilidade de "mudar o mundo" por meio da paz, da liberdade e do amor, criticando a crueldade causada pelas guerras mundiais como também o consumismo desenfreado. Questão semelhante pode ser observada nos versos da canção Índios de Renato Russo: "e o futuro não é mais como era antigamente". Fugindo ao passado, marcado pela utopia, transparece, no canto desta geração, o desencanto do presente, a ameaça assustadora da aids, a crise de identidade e, principalmente, a falta de perspectiva.

A canção tornou-se um ícone da década de 1980, marcada pela falta de impacto das ideologias, a ausência de ilusões, a aids, delineando um perfil conturbado da chamada "geração perdida". Segundo Aguiar, a canção de Cazuza e Frejat "acaba revelando as inquietações de um poeta a quem não escapou a observação forte do individualismo nas pessoas, sintoma de uma época desesperançada. Por esta razão, a canção marcou um dos momentos mais criativos do rock dos anos 1980" (Aguiar, 1996, p. 55).

\footnotetext{
${ }^{3}$ Conforme a leitura de Campos (1997) e Vargas (1999).
} 
Ainda sob o viés sócio-político, encontramos também referências ao espaço, ou falta de espaço, ocupado pela geração pós-ditadura, a "geração perdida". Assim, os próprios artistas se autorretratam nas canções, no sentido de buscar um lugar ao sol, mesmo sem saber por onde e como encontrar a saída:

Somos os filhos da revolução

Somos burgueses sem religião

Nós somos o futuro da nação

Geração Coca-cola (Russo, 1985).

A expressão "geração Coca-cola" faz referência aos acordos realizados entre o governo militar e o EUA (MEC-USAID), com vistas à reformulação do ensino público no Brasil e pode ser focalizada como metáfora dos sujeitos (no caso, a juventude pós-ditadura) que nasceram e cresceram no período:

Quando nascemos fomos programados

A receber o que vocês nos empurraram

Com os enlatados dos USA, de 9 às 6.

Desde pequenos nós comemos lixo

Comercial e industrial

Mas agora chegou nossa vez -

Vamos cuspir de volta o lixo em cima de vocês (Russo, 1985).

Os versos acima mostram dois momentos da história do sujeito da canção: de passividade ("programados a receber") e de ação ("vamos cuspir.."). Ao passado, representado como período de "dominação", contrapõe-se o presente ("agora") como possibilidade de mudança, cuja voz parece emergir de sob os escombros da repressão. Nesse fragmento, percebe-se, claramente, a oposição entre o "nós" (o sujeito jovem) e o "vocês" (os militares). De que lugar esse "nós" enuncia? Qual a posição discursiva adotada? Essa postura de negação e ruptura com a geração militar, materializada no enunciado da canção, produz efeitos de demarcação territorial e, sobretudo, de instauração de identidades. São posições discursivas, cujos direcionamentos caminham no sentido de dar voz e ter voz enquanto integrantes da juventude pós-ditadura. Juventude esta que seguiu o caminho do rock, e nele, cada qual (grupo/banda), a seu modo, expôs as contra- 
dições e os impasses dos anos 1980:

A gente não sabemos escolher presidente

A gente não sabemos tomar conta da gente

A gente não sabemos nem escovar os dentes

Inútil, a gente somos inútil

A gente escreve peça e não consegue encenar

A gente faz música e não consegue gravar

A gente escreve livro e não consegue publicar

A gente faz filho e não consegue criar

Inútil, a gente somos inútil (Moreira, 1985).

Os versos da canção soam altamente irônicos, explicitando um panorama da sociedade que não muda, sempre cercando as possibilidades e demarcando, cada vez mais, a desigualdade social. Elementos que delimitam a dificuldade de sobrevivência ("a gente não sabemos tomar conta da gente"), o sentimento de inutilidade ("inútil, a gente somos inútil") e a dificuldade de criação ("encenar", "gravar", "publicar" e "criar"). É interessante observar a constante repetição de determinadas expressões ao longo do texto, recurso intensificador da crítica proposta.

O texto compõe um painel caótico do cotidiano, em que os sujeitos ("a gente") encontram-se inutilizados perante o mundo e impotentes para agir, mas, ao mesmo tempo, critica a falta de condições propícias para a ação e, consequentemente, para a sobrevivência. Tal questão torna-se expressiva mediante o uso do termo "a gente", de caráter universalizante, e que, no texto em questão, delimita e/ou explicita a posição dos sujeitos no discurso em questão. Instaura-se um jogo ambíguo entre materializar pré-julgamentos atribuídos ao jovem (inútil/alienado) e a condição de "inutilidade" de se viver em uma sociedade caracterizada pela falta de espaço e visibilidade social.

Para Aguiar (1994), o conteúdo veiculado nas letras das canções de rock apresenta-se de forma explícita, da maneira mais direta possível, sem grandes metáforas e/ou imagens. Para o crítico em questão, as canções de rock, no tocante ao elemento poético, funcionam como mais uma mercadoria e, como tal, descartável. Evidentemente, como já comentamos, as diferentes produções culturais, inevitavelmente, passam pelo sistema mercadológico, mas, a partir de então, 
considerar tudo como "produto descartável" é outra história. Conforme Aguiar, as críticas nas canções de rock são realizadas diretamente, o que não podia acontecer vinte anos atrás durante o regime militar. Ao contrário do Rock, considerado como música da abertura política, as Canções de Protesto e da Tropicália (década de 1960/1970) tiveram que driblar a censura utilizando-se de recursos textuais (metáforas, imagens, etc.) fortemente elaborados. Mesmo assim alguns músicos, como Caetano Veloso, Gilberto Gil, Chico Buarque, Geraldo Vandré, foram presos e sofreram repressões. Embora diferentes entre si, as produções musicais das décadas de 1960, 1970 e 1980 guardam certa proximidade e/ou influência, porém não podemos desconsiderar o contexto de produção das canções de protesto, da tropicália e do rock, principalmente, do que foi produzido na década de 1980. Enquanto os dois primeiros enfrentavam "as ameaças" dos censores, o último surgiu em um momento "pós-censura". Não só o contexto de produção é diferente, mas também as formas de recepção e, consequentemente, as formas de interpretação de e para cada segmento musical.

Nesse sentido, a diferença não reside propriamente no uso das figuras de linguagem. Tanto o rock quanto as canções de protesto e a tropicália usam metáforas, linguagem conotativa, etc., cada qual a seu modo. O elemento diferenciador reside nas formas de interpretação para cada contexto de produção. Na ditadura, os censores interpretavam as canções de Chico Buarque, Caetano Veloso, Geraldo Vandré, por exemplo, buscando e/ou perseguindo qualquer dado ou palavra que fosse considerado "um atentado aos bons costumes sociais" e, mais especificamente, temáticas contrárias ao poder militar. No caso do rock, a situação é outra e, em diversos momentos, algumas bandas procuraram, no período posterior à "abertura política", resgatar criticamente fatos ligados ao período militar. Foi também o momento de autodefinição geracional, de repensar o presente, etc.

Por mais que as letras das canções de rock sejam facilmente "consumíveis", é possível constatar momentos expressivos dentre uma infinidade de canções, em que o discurso-poético, ora sentimental ora social, consegue delinear um painel crítico da década de 1980.

Várias bandas dos anos 1980 fazem uma aposta na reconquista de uma memória destruída durante o regime militar e movem seus esforços a partir de uma visão alegre de conquistar o presente-com a fala que se tem, com o canto que se tem, 
com a expressão poética dada no momento (Souza, 1995, p. 67).

Esse argumento responde a várias críticas negativas feitas ao rock, classificando-o como "doença infantil da MPB", "nova jovem guarda", dentre outros argumentos que procuraram analisá-lo por meio de concepções não condizentes com o contexto caótico dos anos 1980. Todavia, analisar o rock seguindo orientações metodológicas e/ou teóricas, utilizadas para discutir as canções da Bossa Nova, do Tropicalismo, da Canção de Protesto e/ou da própria poesia brasileira, torna o fato mais complicado do que parece, pois o rock reflete as condições de produção do contexto no qual surgiu, isto é, o rock desenvolveu-se "com a fala que se tem, com o canto que se tem e com a expressão poética dada no momento", conforme coloca Souza (1995, p. 67).

Para o poeta crítico Ítalo Moriconi, o rock dos anos 1980 configurou-se como uma expressão poética de uma juventude que não vivera 68, mas que ainda preservava seus mitos. Destaque para Arnaldo Antunes, Cazuza, Renato Russo, dentre outros. Ainda segundo Moriconi, esses autores "forneceram o mesmo tipo de pão essencial prodigamente distribuído vinte anos antes por Caetano e Chico" (Moriconi, 1998, p. 17).

Nessa perspectiva, a canção Comida, do grupo Titãs, torna-se expressiva e, por que não dizer, representativa de uma outra faceta do rock brasileiro, um rock mais amadurecido tanto nos temas quanto na linguagem.

Bebida é água

Comida é pasto

Você tem sede de quê?

Você tem fome de quê?

A gente não quer só comida

A gente quer comida, diversão e arte

(...)

A gente não quer só comer

A gente quer comer e fazer amor

A gente não quer só comer

A gente quer prazer pra aliviar a dor (Fromer; Antunes et Brito, 1987). 
A letra explicita o desejo do sujeito da canção (a gente) de ter acesso a outras formas de conhecimento, diversão e arte etc. A construção paralelística mantém a mesma estrutura sintática, realçando a gradação constante no texto e o teor crítico e poético proposto no discurso-poético da canção. Em relação ao sujeito, o termo "a gente" veicula uma idéia genérica (vários "eus"), que pode englobar um grupo social bastante amplo: talvez a juventude dos anos 1980.

Essa marca "a gente", bem como outras expressões do mesmo teor, parece funcionar como um termo emblemático de um tipo de subjetividade característico do universo jovem. São sujeitos, na maioria jovens, fazendo um tipo de música, criando expressões representativas desse universo. Ao utilizar a expressão "a gente não quer", percebe-se uma oposição entre esta subjetividade (sujeito jovem) em oposição ao outro, provavelmente do setor político (governo), ou de um certo setor, para o qual "diversão e arte para qualquer parte" não estabelecem vínculos com um projeto social maior.

\section{Considerações finais}

A década de 1980 configurou-se como um período conturbado na política e cultura brasileira, porque foi o momento pós-abertura, marco do fim de vinte anos de ditadura militar no Brasil. No plano cultural, esse período aponta para a estética da pós-modernidade e, conseqüentemente, para a emergência de outras manifestações sociais (novas subjetividades, novos cenários), que surgem de vários pontos com propostas diferentes, inaugurando outro momento pautado pela coexistência plural de poéticas possíveis.

Estética e politicamente, o rock dos anos 1980, nas vozes dos compositores aqui estudados, posicionou-se criticamente frente às questões vigentes em seu momento histórico, delineando perfis de subjetividade (identidade jovem), por meio das posições-sujeito assumidas e pelo canto/leitura do país no período em questão.

Nesse sentido, esse estudo teve como proposta um breve levantamento de alguns compositores e bandas do referido período. Por meio deste trabalho, foi possível constatar, pelo menos nos textos discutidos, esse movimento de subjetividade jovem, caracterizado pela ruptura com a geração militar e pela busca de espaço (ter voz) no cenário nacional. São questões que ainda merecem um 
estudo mais detalhado, tendo como foco um número maior de composições e bandas de rock deste período.

\section{Discografia}

CAZUZA et FREJAT. Ideologia. In CAZUZA. Ideologia. Rio de Janeiro: Poligram, 1988.

MOREIRA, Roger Rocha. Inútil. In ULTRAJE A RIGOR. Nós vamos invadir sua praia. Rio de Janeiro: WEA, 1985.

FROMER, Marcelo, ANTUNES, Arnaldo et BRITTO, Sérgio. Comida. In TITÃS. Jesus não tem dentes no país dos banguelas. Rio de Janeiro: WEA, 1987.

RUSSO, Renato. Geração coca-cola. In URBANA, Legião. Legião urbana. São Paulo: Emi-Odeon, 1985.

\section{Referências Bibliográficas}

AGUIAR, Joaquim. Panorama da Música Popular Brasileira: da Bossa Nova ao Rock dos anos 1980. In SOSNOWSKI, Saulet SCHWARTZ, Jorge. (Orgs.). Brasil: o trânsito da memória. São Paulo: Edusp, 1994.

DAPIEVE, Arthur. Brock. O rock brasileiro dos anos 1980. Rio de Janeiro: Editora 34, 1995. FERNANDES JÚNIOR, Antônio. Intertextualidade e movimento de leitura em canções de Renato Russo. Dissertação (Mestrado) - Unesp. Araraquara, 2001.

FOUCAULT, Michel. Arqueologia do Saber. 4a edição. Rio de Janeiro: Forense Universitária, 1995.

. A Ética do cuidado de si como prática de liberdade. In MOTTA, Manoel Barros. (Org.). FOUCAULT, Michel. Ditos \& Escritos V. Rio de Janeiro; Forense Universitária, 2004. p. 264-287.

GREGOLIN, Maria Rosário. Foucault e Pêcheux na construção da análise do discurso: diálogos e duelos. São Carlos: Claraluz, 2004.

IANNI, Octávio. Metáforas da Globalização. In: ORLANDI, Eni. et alli. Sociedade e linguagem. Campinas: Editora da Unicamp, 1997. p. 49-63.

MAIA, Cristiano Escobar. A nossa geração perdida. Santa Catarina: Univali, 2000.

MORICONI, Ítalo. Pós-Modernismo e volta do sublime na poesia brasileira. In PEDROSA, Célia. (Org.). Poesia Hoje. Niterói: EdUFF, 1998.

ORTIZ, Renato. O mercado de bens simbólicos. In A moderna tradição brasileira. Culura e indústria cultural. 5a edição. São Paulo: Braziliense, 1994. p. 113-148.

PELLEGRINI, Tânia. A Mídia. In A imagem e a letra: aspectos da ficção brasileira contem- 
porânea. Campinas: Mercado de Letras; São Paulo: Fapesp, 1999. p. 175-213.

SOUZA, Antônio Marcus Alves. Cultura rock e arte de massa. Rio de Janeiro: Diadorim, 1995.

VARGAS, Christian. Os anjos decaídos: uma arqueologia do imaginário pós-utópico nas canções da Legião Urbana. In: COSTA, C. B. \& MACHADO, M. S. K. (Orgs.). Imaginário e história. São Paulo: Marco Zero; Brasília: Paralelo 15, 1999. p.171-205.

WISNIK, José Miguel. La gaya ciência: literatura y música popular en Brasil. In: Revista de Occidente. Madrid, n. 174, nov. 1995. p 53-72. 